\title{
Facade Refurbishment For Energy Saving In Tube Houses A case study in Hanoi, Vietnam
}

\author{
Phan Anh Nguyen $^{1, *}$, Regina Bokel $^{1}$, and Andy van den Dobbelsteen ${ }^{1}$ \\ ${ }^{1}$ Architectural Engineering \& Technology Department, Faculty of Architecture \& the Built Environment, TU Delft, Netherlands
}

\begin{abstract}
This paper investigated the energy upgrade potentials of different facade refurbishment options in tube houses of Vietnam. A calibrated Design Builder model was created to simulate energy performance of different cases. Vietnamese technical regulation of energy efficiency building and Dutch standards were the two main guidelines for selection of refurbishing measures. The simulation results showed that applying Vietnamese technical regulation can save up to $9 \%$ of energy for heating and cooling. More interestingly, highly insulated facade that followed Dutch standards led to much more favourable results of $21 \%$ reduction in air conditioner consumption. It is worth to note that such improvement was by far only achieved with a night-time operation of air-conditioner, as how the system was working in the reference house. Shading devices were also tested on a southwest facade window. Horizontal overhang had very limited benefit of less than $6 \%$ reduction in cooling energy. An external blind could save up to $12.6 \%$ of cooling energy. However, as all three shading types had a negative effect in heating season, the maximum annual saving was only $7 \%$.
\end{abstract}

\section{Introduction}

The residential sector, which accounts for more than $31 \%$ of total energy consumption [1], has been addressed as one of the most important sectors that can reduce the total energy consumption in Vietnam. It is estimated that there are more than 22 million residential units in Vietnam [2]. There is a great demand for refurbishment strategies for energy upgrading the current Vietnamese housing stock. Among those dwellings, the tube house, or attached row house, is the most dominant housing typology which accounts for more than $70 \%$ of the total living units [2]. This paper investigates the energy upgrade potential of different façade refurbishment options for Vietnamese tube houses.

\section{Literature study}

Facade refurbishment for energy efficiency has been profoundly investigated and was proved to bring many benefit to the energy upgrade of the current housing stock. A facade refurbishment toolbox was developed to estimate energy performance of different design measures in early design stages in temperate climate [3]. Several potential general refurbishment design strategies were defined for energy efficiency in the tube houses of Vietnam [4]. Many of them involved the renovation of the existing building envelope. Measures include thermal insulation and shading device for the opaque envelope, passive solar gain for windows and glazing area, and natural ventilation and evaporative cooling using green walls and roofs. This paper investigates only thermal insulation and shading devices.

Current thermal comfort theory and air conditioning practice mainly concern the situation where occupants are awake during daytime. However, in residential buildings, people spend a considerable amount of time sleeping and therefore energy consumption of airconditioning during night time is important. Moreover, thermal comfort during night time is different from normal comfort model. Changing thermal insulation of a bedding system affects the optimum operative temperature significantly [5]. A programmed airtemperature change can potentially reduce almost one third of the cooling load during the night [6]. This paper takes into account the sleeping thermal comfort and airconditioning behaviour during the night time. During the model calibration process, heating and cooling patterns were customized accordingly to the actual occupants' behaviour.

\section{Methodology}

A typical tube house was selected as a case study house. It is located in the urban area of Hanoi, the capital of Vietnam, and the plot size is $4 \times 12$ meter. The house is 4-storey high and has 2 facades at the front and rear. It has reinforced concrete frame, $220 \mathrm{~mm}$ brickwork external walls and single glazing windows, see fig. 1. 
On-site measurement was carried out to collect the data of energy consumption of the equipment, indoor and outdoor temperature (see 3.1).

Information about the design and construction of the case study house was gathered to set up a model in Design Builder software version 4.7. The model considered all aspects from the surrounding landscape until the material of a building component. The model was calibrated by the measured data (see 3.2).

The model was simulated with different refurbishment options to investigate energy upgrade compared to the reference case (see $3.3 \& 3.4$ ).

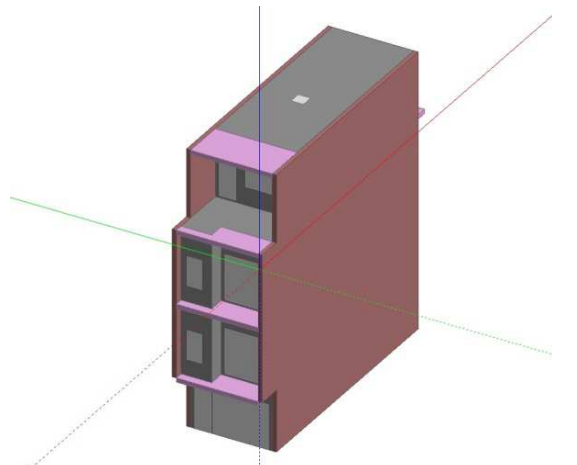

Fig. 1. Design Builder model of a case study house

\subsection{Onsite monitoring}

The building performance was monitored for 2 months, December 2017 and January 2018. Outdoor and indoor temperature and energy consumption were measured by Sense and Source, monitoring equipment that was developed by the Plugwise company, see fig. 2.
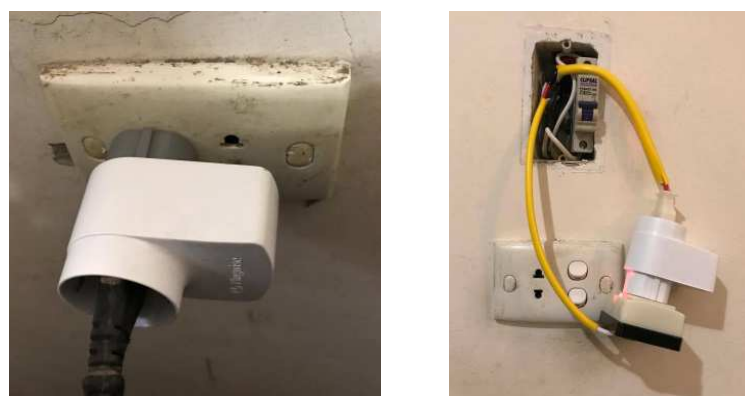

Fig. 2. Plug-wise unit installed for energy measurement Fig. 3 shows the location of the measurement units in the house. Currently, there are only 2 occupants living in the house and they mostly occupy the lowest two floors. The ground floor is mainly equipped with kitchen appliances such as induction cooker, refrigerator, microwave oven. Both the living room and bedroom on the first floor are equipped with air-conditioners that are capable of both heating and cooling. A water boiler is located in the bathroom on the first floor for daily showering. Most of pluggable electrical equipment was measured. The lighting system could not be measured because the cables are inside the walls. A washing machine on the top floor is out of range of the monitoring system hence is also not measured. However, it is rarely in use and can be estimated easily by simple calculation. Monthly energy bills were recorded to quantify consumption of unmeasured equipment.

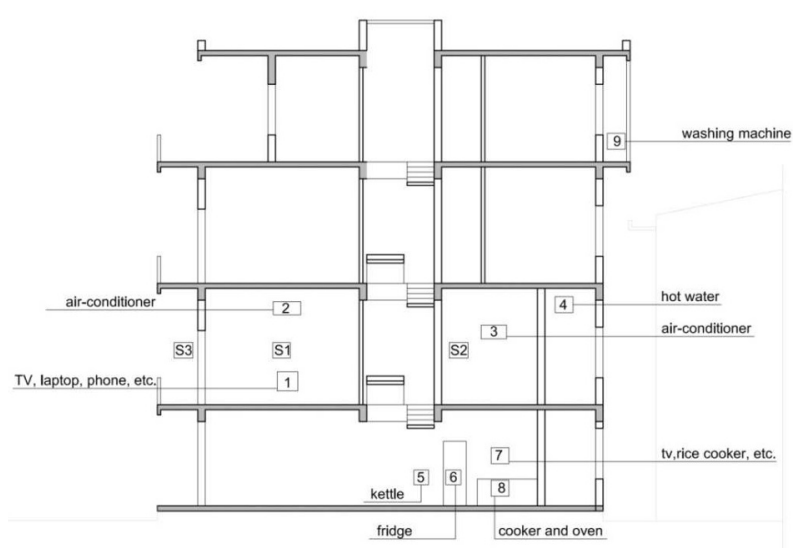

Fig. 3. Locations of the measurement units in the house

\subsection{Model Calibration}

Calibration of a housing model is an important step to check how well the model can predict housing performance by comparing it with data of the actual building.

Table 1. Summary of modifications to the model.

\begin{tabular}{|c|c|}
\hline Run & Recorded changes \\
\hline 1 & Simple model with construction parameters \\
\hline 2 & $\begin{array}{c}\text { Update holiday schedule } \\
\text { Change ventilation setting } \\
\text { Update lighting schedule }\end{array}$ \\
\hline 3 & $\begin{array}{c}\text { Update building orientation } \\
\text { Update infiltration setting }\end{array}$ \\
\hline 4 & $\begin{array}{c}\text { Update new weather data } \\
\text { New setting for air conditioner and infiltration }\end{array}$ \\
\hline 5 & $\begin{array}{c}\text { Update occupant density } \\
\text { Update shading device }\end{array}$ \\
\hline 6 & \begin{tabular}{c} 
Update Heating and cooling setting \\
\hline 7
\end{tabular} \\
\hline
\end{tabular}

The calibration procedure included different steps, see table 1. Onsite-measured outdoor temperature and humidity, along with solar radiation and outdoor wind data which were acquired from the Hanoi meteorological station [7] were used to compose a weather file. Housing information was used to create a model in Design Builder software. Finally, the simulated results were compared with the indoor measurement data to evaluate the accuracy of the model. The correlation between the simulated and measured data was improved by adjusting uncertain input variables within an reasonable range. Those variables are natural ventilation scheme, occupant activities, HVAC system settings, equipment specification. The model is calibrated after 7 calibration runs, where the residual reaches certain threshold 
defined in ASHRAE standards [8], see table 2. It is generally accepted that the statistical approach which applies two statistical indicators - Normalized Mean Bias Error (NMBE) and Coefficient of Variation of Root Square Mean Error CV(RMSE) - is the most reliable measure to verify the calibration [8].

Table 2. Different criteria for calibration runs

\begin{tabular}{|c|c|c|c|c|c|}
\hline Run & $\mathbf{4}$ & $\mathbf{5}$ & $\mathbf{6}$ & $\mathbf{7}$ & ASHRAE \\
\hline NMBE & $1.7 \%$ & $3.4 \%$ & $2.3 \%$ & $0.8 \%$ & $<5 \%$ \\
\hline CV(RMSE) & $5.5 \%$ & $6.0 \%$ & $4.9 \%$ & $3.9 \%$ & $<15 \%$ \\
\hline Regression & 0.52 & 0.54 & 0.71 & 0.75 & $>0.75$ \\
\hline
\end{tabular}

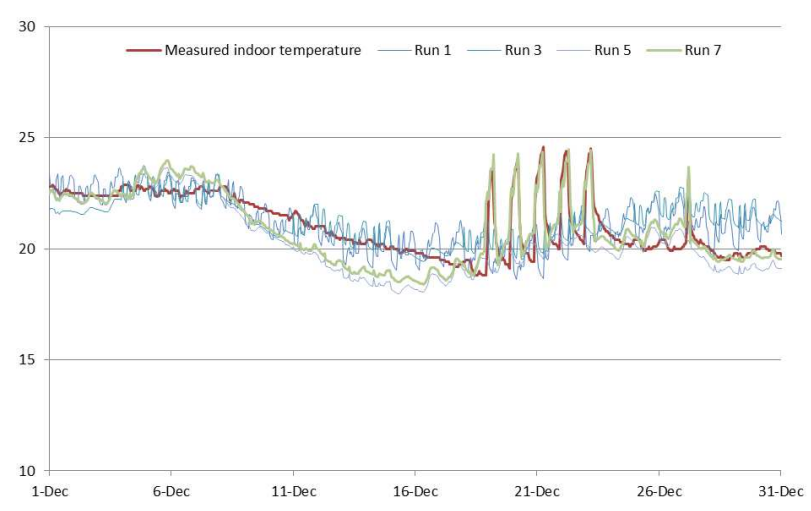

Fig. 4. Bedroom simulated and measured temperatures

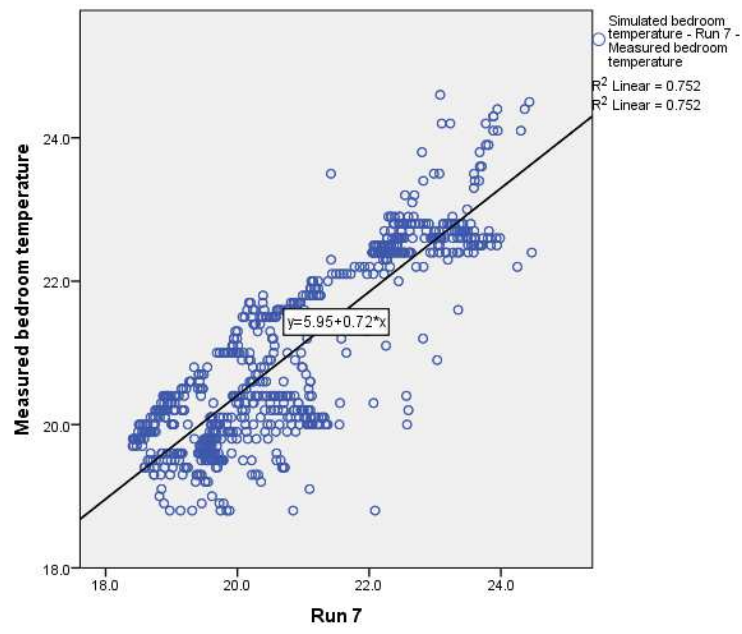

Fig. 5. Bedroom measured \& simulated temperature at run 7 Another important measure to evaluate the model is to use the regression analysis to check to correlation of the measure and simulated data. Actual bedroom temperature and simulated bedroom temperature are plotted in figure $4 \& 5$. The final model at calibration run 7 met the statistical standards and also the bedroom temperature values at run 7 were the closest to the measured data. The model is good enough and is considered to be calibrated.

\subsection{Building Simulation}

In order to examine the different refurbishment measures, full-year simulations of calibrated EnergyPlus models of the house were conducted. Thermal performance and energy performance were simulated. A full calendar year simulation can assess housing performance rather than only the heating or cooling period. The EPW weather file of Hanoi was used, instead of the measured weather file. Calibrated EnergyPlus model of the house was also modified to fit with a one-year scenario. HVAC system was also scheduled in a more simple way, operated by schedule and temperature - triggered mechanism. The heating setpoint was $21.5^{\circ} \mathrm{C}$ and the cooling set point was $28.5^{\circ} \mathrm{C}$. Currently, only two persons occupy one bedroom in the house and only one air-conditioner in this bedroom is active. However, in the simulation scenario, 2 out of 3 bedrooms were occupied, which represents a typical family situation in a similar size tube house in Vietnam. Therefore, two air-conditioners were included in the energy consumption calculation.

\subsection{Facade Refurbishment options}

The housing façade includes external walls, roof, external opening/glazing area, and facade components such as shading devices, balcony. Only two bedrooms require heating and cooling in the house, therefore only external walls and glazing openings are considered to be renovated because they are directly connected to the conditioned spaces. The roof construction mainly benefits the performance of the top floor which is currently unconditioned.

Two refurbishment methods are carried out. The first method is the regulation method. One of the objectives of the larger study of the author is to provide recommendation for the energy efficiency regulation for the tubes houses in Vietnam. Therefore, envelop construction recommended by different technical regulations were applied, see table 3. The Vietnamese technical regulation for energy efficiency [9], which only applies to the large-scale buildings, was the first to consider. Dutch standard for the building envelope [10] was also tested as the main author works at TU Delft in the Netherlands.

Table 3. Facade refurbishment options by regulation

\begin{tabular}{|c|c|c|}
\hline & External Walls & Windows \\
\hline $\begin{array}{c}\text { Current } \\
\text { detail }\end{array}$ & $\begin{array}{c}220 \mathrm{~mm} \text { brick work, } \\
\text { no insulation, } \mathrm{U}= \\
3.197 \mathrm{~W} / \mathrm{m} 2 \mathrm{~K}\end{array}$ & $\begin{array}{l}\text { Single glazing, } \mathrm{U} \\
=5.778 \mathrm{~W} / 2 \mathrm{~K} \\
\mathrm{SHGC}=0.819\end{array}$ \\
\hline $\begin{array}{c}\text { Vietnamese } \\
\text { regulation } \\
\text { 9] }\end{array}$ & $\begin{array}{c}\text { Wall } 1-\mathrm{U} \max \\
\text { W/m2K }\end{array}$ & $\begin{array}{c}\text { Glazing } 1-\text { SHGC } \\
\max =0.63\end{array}$ \\
\hline Example & $\begin{array}{c}\text { Add } 10 \mathrm{~mm} \text { of } \\
\text { extruded polystyrene, } \\
\mathrm{U}=1.682 \mathrm{~W} / \mathrm{m} 2 \mathrm{~K}\end{array}$ & $\begin{array}{c}\text { Double glazing, } \\
\text { SHGC }=0.69 \\
\mathrm{U}=2.7 \mathrm{~W} / \mathrm{m} 2 \mathrm{~K}\end{array}$ \\
\hline $\begin{array}{c}\text { Dutch } \\
\text { regulation } \\
{[10]}\end{array}$ & $\begin{array}{c}\text { Wall } 2-\text { Umax }= \\
0.29 \mathrm{~W} / \mathrm{m} 2 \mathrm{~K} \\
\mathrm{Rc}=3.5 \mathrm{~m} 2 \mathrm{~K} / \mathrm{W}\end{array}$ & $\begin{array}{l}\text { Glazing } 2 \text { - Umax } \\
=2.2 \mathrm{~W} / \mathrm{m} 2 \mathrm{~K}\end{array}$ \\
\hline
\end{tabular}




\begin{tabular}{|c|c|c|}
\hline & $100 \mathrm{~mm}$ brick work, & \\
Example & $120 \mathrm{~mm}$ XPS & Double glazing, \\
& extruded polystyrene, & Dou mm concrete \\
& SHGC $=0.67$ \\
& block, plastering, $\mathrm{U}=$ & $\mathrm{U}=2.1 \mathrm{~W} / \mathrm{m} 2 \mathrm{~K}$ \\
$0.26 \mathrm{~W} / \mathrm{m} 2 \mathrm{~K}$ & \\
\hline
\end{tabular}

Adding shading devices is the second method. Shading devices are a popular low-cost solution to prevent direct solar gain and overheating in summer. The benefit of adding shading devices to the bedroom on the second floor was investigated. The simulation calculated the performance of the bedroom when a $0.5 \mathrm{~m}$ and $1 \mathrm{~m}$ overhangs were added. Furthermore, an external blind with medium reflective slats (solar reflectance of 0.5 ) was also investigated.

\section{Results and Discussion}

\subsection{Measurements Results}

Fig. 6 illustrates the measured temperature in the month of December 2017. The outdoor temperature ranged from $15^{\circ}$ to $25^{\circ} \mathrm{C}$. The indoor temperature did not vary much and reached a low at $19^{\circ} \mathrm{C}$. From the 18 th until the 23rd and on the 27th of December, the air-conditioner was turned on during the night time in the bedroom. This explains the fluctuation of indoor temperature in Fig. 6. The bedroom air-conditioner was only used for a number of hours during the night.

The house utilizes electricity as the main and only energy source for daily use. High consumption equipment are the air-conditioners and the boiler for domestic hot water. Figure $7 \& 8$ show the monthly energy consumption in 2017 and energy consumption by the appliances in December 2017.

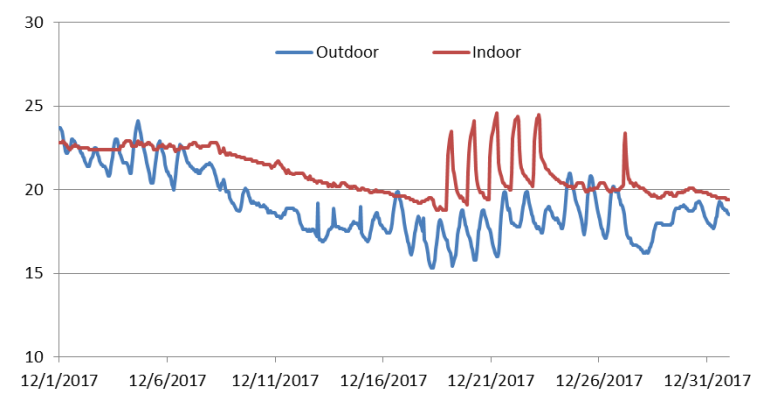

Fig. 6. On-site measured outdoor and indoor temperature

Total actual energy consumption in 2017 was $4518 \mathrm{kWh}$ and the average monthly consumption was $376 \mathrm{kWh}$. Energy use in summer time was generally higher than that in winter. Peak energy consumption was in May but not June or July due to the summer vacation. Energy use in March was highest because the house was occupied by guests during that period.

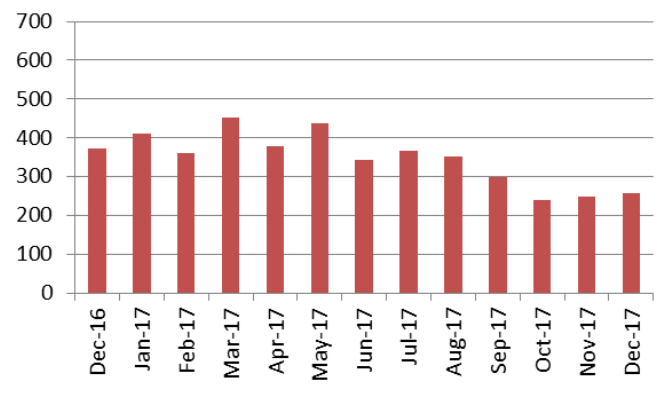

Fig. 7. Monthly energy consumption in 2017 (kWh )

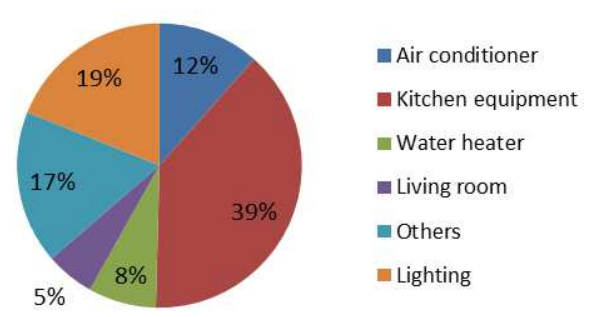

Fig. 8. Appliances consumption December 2017

Total energy use in December 2017 was $258 \mathrm{kWh}$. Only $11.6 \%$ of the energy was used for heating. Kitchen appliances (refrigerators, induction cooker, ovens) accounted for the largest energy use (38.8\%). The lighting system also consumed a considerable amount of energy (18.9\%).

\subsection{Simulation Results}

Simulated consumption of the reference house is shown in table $4 \&$ fig. 9. Annual electricity usage is around $5500 \mathrm{kWh}$. The amount of energy spent for heating and cooling accounts for one-third of the total energy consumption. Electrical appliances takes the largest share $(45 \%)$ while lighting and hot water consume $15 \%$ and $7 \%$ of total energy consumption, respectively.

Table 4. Simulated annual consumption - reference house

\begin{tabular}{|c|c|c|}
\hline & Energy (kWh) & Percentage (\%) \\
\hline Heating & 575 & $10 \%$ \\
\hline Cooling & 1244 & $22 \%$ \\
\hline Lighting & 843 & $15 \%$ \\
\hline Equipment & 2448 & $44 \%$ \\
\hline Hot water & 397 & $7 \%$ \\
\hline Total & 5509 & $100.0 \%$ \\
\hline
\end{tabular}

\subsection{Regulation based refurbishment}

The ultimate goal of the research is to reduce energy consumption in the house therefore the analysis focuses on how much energy is saved by utilizing different refurbishment methods. Table 5 presents simulated heating and cooling demand of the houses after refurbishment. Retrofitting the facade accordingly to the current Vietnamese technical regulation (wall 1 and glazing 1) does show some improvements but minor (less than $6 \%$ of total heating and cooling energy). 
Double glazing windows do not shows much different in energy performance. While heating energy varies less than $2.6 \%$, cooling energy is reduced by less than $4.4 \%$ and total heating and cooling performance is improved by $3 \%$ for Glazing 1 and almost $4 \%$ for Glazing 2 .

Table 5. Simulated energy consumption of different facades*

\begin{tabular}{|c|c|c|c|c|c|c|}
\hline & \multicolumn{2}{|c|}{ Heating/saving } & \multicolumn{2}{c|}{ Cooling/saving } & \multicolumn{2}{c|}{ HVAC/ saving } \\
\hline Current & 577 & - & 1245 & - & 1823 & - \\
\hline Wall 1 & 530 & $8.2 \%$ & 1180 & $5.3 \%$ & 1710 & $6.0 \%$ \\
\hline Wall 2 & 439 & $24 \%$ & 1081 & $13.2 \%$ & 1521 & $16.6 \%$ \\
\hline Glazing 1 & 564 & $2.3 \%$ & 1205 & $3.3 \%$ & 1769 & $3.0 \%$ \\
\hline Glazing 2 & 562 & $2.6 \%$ & 1191 & $4.4 \%$ & 1754 & $3.8 \%$ \\
\hline W1 + G1 & 516 & $10.7 \%$ & 1137 & $8.7 \%$ & 1653 & $9.3 \%$ \\
\hline W2 + G2 & 423 & $26.8 \%$ & 1012 & $18.8 \%$ & 1435 & $21.3 \%$ \\
\hline
\end{tabular}

* see table 3 for the values of walls and windows

Although applying Vietnamese regulation on external walls and windows separately does not show significant improvement, utilizing both of them at the same time brings acceptable results, $9 \%$ reduction in airconditioning consumption.

Applying Dutch standards into facade refurbishment shows desirable reduction in energy consumption. Highly insulated walls as followed the Dutch requirement shows significant reduction in heating demand $(24 \%)$ and cooling demand (13\%). Combining with double glazing windows, heating demand is expected to be reduced by $26.8 \%, 18.8 \%$ for cooling energy and $21 \%$ for both heating and cooling.

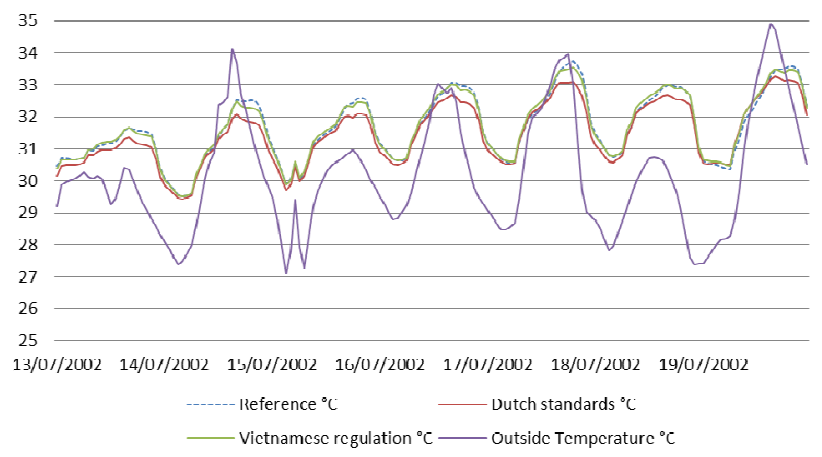

Fig. 9. Simulated bedroom temperature during summer week Regarding thermal performance, bedroom temperatures of the reference case and refurbished case following Vietnamese and Dutch regulations during a summer week are plotted in fig. 9. Air-conditioner was off. As can be seen from the graph, thermal performance of the Vietnamese regulation refurbished case is very similar to the reference case. Highly insulated facade following Dutch regulation also shows little improvement during night-time period but reduces peak temperature during daytime up to $0.8^{\circ} \mathrm{C}$. Indifferences in night-time temperatures support the hypothesis that reduction in cooling energy is due to the "cold loss prevention" rather than reducing indoor air temperature. Lower peak temperature during summer time can be explained by the thermal mass provided by a $100 \mathrm{~mm}$ layer of concrete block that was added to the existing construction. It also suggests potential further energy saving if airconditioner is used during the day.

\subsection{Shading device refurbishment}

As described above, three different types of shading options were simulated in the model. Results of energy performance are plotted in table 6 .

Simulation results reveal that, despite being regarded as an effective bioclimatic design measure, shading device leads to limited improvement in energy performance. All of the shading options have negative effect during heating season because there is less direct solar heat gain. A 0.5-meter and a 1-meter horizontal shading device only reduce cooling demand by $3 \%$ and $6 \%$ respectively. Shading 3, which includes an external blind shows a 12.6 reduction in cooling demand but increases heating demand by $5.1 \%$. In general, shading devices have a maximum reduction of $7 \%$ in total heating and cooling energy.

Table 6. Simulated energy consumption of the shading options

\begin{tabular}{|c|c|c|c|c|c|c|}
\hline & \multicolumn{2}{|c|}{ Heating/saving } & \multicolumn{2}{c|}{ Cooling/saving } & \multicolumn{2}{c|}{ HVAC/ saving } \\
\hline Current & 577 & - & 1245 & - & 1823 & - \\
\hline $\begin{array}{c}0.5 \mathrm{~m} \\
\text { overhang }\end{array}$ & 584 & $-1.3 \%$ & 1208 & $3.0 \%$ & 1792 & $1.7 \%$ \\
\hline $\begin{array}{c}1 \mathrm{~m} \\
\text { overhang }\end{array}$ & 592 & $-2.6 \%$ & 1171 & $6.0 \%$ & 1764 & $3.2 \%$ \\
\hline $\begin{array}{c}\text { External } \\
\text { blind }\end{array}$ & 607 & $-5.1 \%$ & 1089 & $12.6 \%$ & 1696 & $7.0 \%$ \\
\hline
\end{tabular}

In this simulation, an external blind works more effectively than an overhang because the window is oriented to the southwest where the sun angle is very low in the afternoon. By then, the horizontal shading devices are less likely to block as much direct solar radiation as an external window blind. Therefore, selecting an appropriate shading device type is important to achieve desirable results in energy performance.

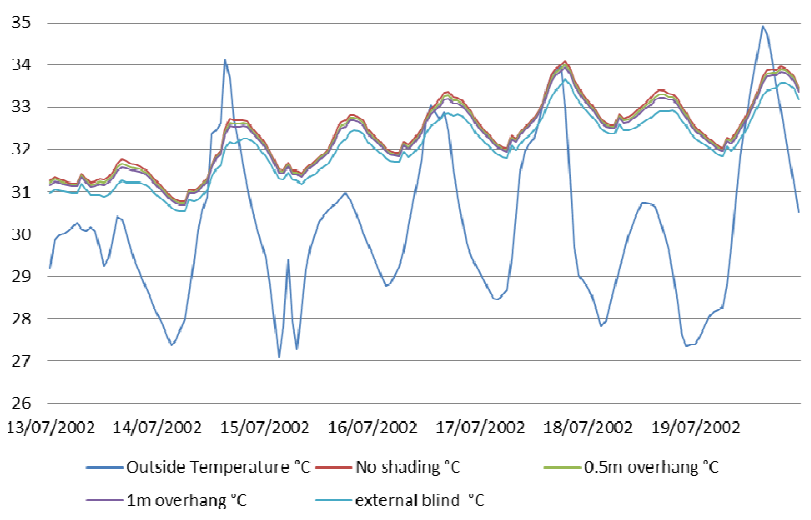

Fig. 10. Simulated bedroom temperature with different types of shading

Shading device also helps improve indoor environment in the bedroom, though little. Fig. 10 plots the bedroom temperature during a summer week of July. The overhangs help reduce the bedroom temperature by 
approximately $0.1^{\circ} \mathrm{C}$ while the external blind brings the temperature down by up to $0.3^{\circ} \mathrm{C}$.

\subsection{Discussion}

The benefit of highly insulated facade during the heating period is foreseen but its notable reduction in cooling demand is quite promising, considering the fact that it gives much more improvement compared to shading devices performance, the well-known believed-to-beeffective measure. This can be explained by the operation schedule of the air conditioner system or the occupant behaviour. The air conditioner is only turned on at nights and when it is necessary. Therefore, bioclimatic measures that help improve indoor climate during day time is less relevant to energy consumption. Highly insulated facade, on the other hand, helps prevent the "cold loss" and the sensible cooling helps reduce cooling demand during the nights. However, energy performance was only simulated with night time air-conditioning. Further investigation on the effect of highly insulated facade on daytime air-conditioning performance is recommended to confirm the benefit of such refurbishment options.

\section{Conclusion}

This paper investigated the energy upgrade potential of different facade refurbishment options. A calibrated Design Builder model was created to simulate energy performance of different cases. Vietnamese technical regulation of energy efficient buildings and Dutch standards were the two main guidelines for the selection of refurbished facade, along with shading device renovation.

The simulation results showed that applying the Vietnamese technical regulation, which is currently only applied to large-scale building, can save up to $9 \%$ of energy for heating and cooling. More interestingly, highly insulated facade that followed the Dutch standard led to much more favourable results of $21 \%$ reduction in air conditioner energy consumption. It is worth to note that such an improvement was achieved with a nighttime operation of air-conditioner only, as this is how the system was working in the reference house. The bedroom thermal performance suggests that the highly insulated facade helps to reduce the energy consumption by the "cold loss prevention" effect. Day-time airconditioner usage might also be improved due to the lower peak temperature.

On the other hand, shading devices were tested on a southwest facade window. Despite being regarded as an effective refurbishing measure, horizontal overhang had very limited benefit of less than $6 \%$ reduction in cooling energy. An external blind can save up to $12.6 \%$ of cooling energy. However, as all three shading types had a negative effect in the heating season, the maximum annual saving was only $7 \%$.

\section{References}

1. International Energy Agency (IEA), [Online], Available:http://www.iea.org/statistics/statisticssearch/re port/?year=2012\&country=VIETNAM \& product=Balanc es (accessed15 October 2015) (2012).

2. General Statistics Office of Vietnam (GSO). The 2009 Population and Housing Census of Viet Nam, Hanoi (2010).

3. T. Konstantinou. Façade Refurbishment toolbox. (PhD dissertation), Delft University of Technology (2014).

4. P.A. Nguyen, R. Bokel \& A. van den Dobbelsteen. Refurbishing houses to improve energy efficiency Potential in Vietnam. Passive Low Energy Architecture 2017 conference proceedings, pp. 4204-4211 (2017).

5. Z. Lin \& S. Deng. A study on the thermal comfort in sleeping environments in the subtropics - Developing a thermal comfort model for sleeping environments. B\&E 43, pp. 70-81 (2008).

6. L. Lan et al. The effects of programmed air temperature changes on sleep quality and energy saving in bedroom. E\&B 129, pp. 207-214 (2016).

7. World Bank. Vietnam-Solar Radiation Measurement Data, available at: https://energydata.info/dataset/esmap-solarmeasurements-in-vietnam" accessed on 10/2/2018 (2017).

8. A. T. Nguyen (2013). Sustainable housing in Vietnam: Climate responsive design strategies to optimize thermal comfort. (PhD dissertation), University of Leige.

9. Ministry of Construction (MOC). QC 09:2013/BXD: National Technical Regulation of Energy efficiency buildings, MOC (2013).

10. M. Van Overveld et al. Praktijkboek Bouwbesluit 2012. Sdu Uitgevers BV(2011). 